\title{
Interleukin-10 improves stroke outcome by controlling the detrimental Interleukin-17A response
}

\author{
Marius Piepke1, Bettina H. Clausen², Peter Ludewig ${ }^{1}$, Jonas H. Vienhues ${ }^{1}$, Tanja Bedke ${ }^{3}$, Ehsan Javidi' \\ Björn Rissiek ${ }^{1}$, Larissa Jank ${ }^{1}$, Leonie Brockmann ${ }^{3}$, Inga Sandrock ${ }^{4}$, Karoline Degenhardt ${ }^{1}$, Alina Jander ${ }^{1}$, \\ Vanessa Roth ${ }^{1}$, Ines S. Schädlich ${ }^{1}$, Immo Prinz ${ }^{5}$, Richard A. Flavell ${ }^{6}$, Yasushi Kobayashi ${ }^{6}$, Thomas Renné ${ }^{7}$, \\ Christian Gerloff', Samuel Huber ${ }^{3}$, Tim Magnus $^{1}$ and Mathias Gelderblom ${ }^{1 *}$
}

\begin{abstract}
Background: Lymphocytes have dichotomous functions in ischemic stroke. Regulatory $T$ cells are protective, while IL-17A from innate lymphocytes promotes the infarct growth. With recent advances of T cell-subtype specific transgenic mouse models it now has become possible to study the complex interplay of T cell subpopulations in ischemic stroke.

Methods: In a murine model of experimental stroke we analyzed the effects of IL-10 on the functional outcome for up to 14 days post-ischemia and defined the source of IL-10 in ischemic brains based on immunohistochemistry, flow cytometry, and bone-marrow chimeric mice. We used neutralizing IL-17A antibodies, intrathecal IL-10 injections, and transgenic mouse models which harbor a deletion of the IL-10R on distinct T cell subpopulations to further explore the interplay between IL-10 and IL-17A pathways in the ischemic brain.

Results: We demonstrate that IL-10 deficient mice exhibit significantly increased infarct sizes on days 3 and 7 and enlarged brain atrophy and impaired neurological outcome on day 14 following IMCAO. In ischemic brains IL-10 producing immune cells included regulatory T cells, macrophages, and microglia. Neutralization of IL-17A following stroke reversed the worse outcome in IL-10 deficient mice and intracerebral treatment with recombinant IL-10 revealed that IL-10 controlled IL-17A positive lymphocytes in ischemic brains. Importantly, IL-10 acted differentially on $a \beta$ and $\gamma \delta$ T cells. IL-17A producing CD4 ${ }^{+} a \beta$ T cells were directly controlled via their IL-10-receptor (IL-10R), whereas IL-10 by itself had no direct effect on the IL-17A production in $\gamma \delta T$ cells. The control of the IL-17A production in $\gamma \delta T$ cells depended on an intact IL10R signaling in regulatory T cells (Tregs).
\end{abstract}

Conclusions: Taken together, our data indicate a key function of IL-10 in restricting the detrimental IL-17A-signaling in stroke and further supports that IL-17A is a therapeutic opportunity for stroke treatment.

Keywords: Stroke, Ischemia, Inflammation, T cells, Interleukin-10, Interleukin-17

*Correspondence: m.gelderblom@uke.de

${ }^{1}$ Department of Neurology, University Medical Center HamburgEppendorf, Martinistraße 52, 20246 Hamburg, Germany

Full list of author information is available at the end of the article

\section{Background}

Worldwide, stroke is one of the leading causes of mortality and sustained disability, with 5.5 million deaths and 11 million disability-adjusted life-years in 2016 [1].

Inflammation is a key component of stroke pathophysiology, with dichotomous effects on the affected tissue. original author(s) and the source, provide a link to the Creative Commons licence, and indicate if changes were made. The images or other third party material in this article are included in the article's Creative Commons licence, unless indicated otherwise in a credit line to the material. If material is not included in the article's Creative Commons licence and your intended use is not permitted by statutory regulation or exceeds the permitted use, you will need to obtain permission directly from the copyright holder. To view a copy of this licence, visit http://creativecommons.org/licenses/by/4.0/. The Creative Commons Public Domain Dedication waiver (http://creativeco mmons.org/publicdomain/zero/1.0/) applies to the data made available in this article, unless otherwise stated in a credit line to the data. 
In the early stages, highly conserved pro-inflammatory pathways lead to a worsening of the initial tissue damage, whereas protective mechanisms are involved in tissue repair and ischemic tolerance in the long term [2].

Among the inflammatory cascades, which drive the early sterile immune response, IL-17A holds an important role. Following stroke, IL-17A is mainly produced by innate-like $\gamma \delta \mathrm{T}$ cells. By driving the expression of neutrophil attracting chemokines [e.g., C-X-C motif chemokines (CXCL-1)], IL-17A is crucial for the amplification of the local inflammatory response in the first hours, resulting in a worsened neurological outcome [3, 4]. However, IL-17A levels and numbers of infiltrating neutrophils already decrease 4 days after ischemia [5]. Immunological mechanisms that limit the IL-17A-dependent inflammatory response are largely unknown. Among potential anti-inflammatory pathways, IL-10 holds a prominent role, due to its strong immunomodulatory and neuroprotective effects $[6,7]$. In stroke, IL-10 has been shown to negatively regulate proinflammatory cytokines (e.g., IFN- $\gamma$, TNF- $\alpha$ ), and antigen-presenting cells, including microglia [6]. Although IL-10 and IL17A have opposing effects on stroke outcome, it is largely unknown whether these two cytokines interact. Studies from models of autoimmunity $[8,9]$ indicate that regulatory $\mathrm{CD}^{+} \mathrm{T}$ cells and IL-10 represent a fundamental mechanism for regulating IL-17A. It has been shown that IL-10 can directly inhibit the IL-17A production of CD4 ${ }^{+}$ effector T cells [8]. Interestingly, disruption of IL-10 signaling on $\mathrm{CD}^{+}$Tregs [10] and $\mathrm{T}$ regulatory type 1 cells $\left(T_{r} 1\right)$ [11] also reduced their capacity to suppress the Th17 immune response which suggests an indirect suppression via an autocrine feed-forward loop.

Compared to the regulation of $\alpha \beta \mathrm{T}$ cells less is known about IL-10 effects on $\gamma \delta$ T cells. However, Park et al. [12] suggested that Treg cell-derived IL-10 directly suppresses $\mathrm{TCR} \gamma \delta^{+} \mathrm{T}$ cells by limiting their proliferation and IL-17A production in a model of inflammatory bowel disease.

The goal of this study was to analyze the role of the IL-10 signaling for the control of the detrimental IL-17A response in stroke. Our data show that IL-10 plays a key role in regulating IL-17A production in $\alpha \beta$ and $\gamma \delta$ T cells in the ischemic brain. Here, IL-10 acts differentially as $\mathrm{CD}^{+} \mathrm{T}$ cells are directly controlled, whereas intact IL10R signaling on Tregs is required to suppress the IL-17A production in $\gamma \delta$ T cells.

\section{Materials and methods}

\section{Animals}

All animal experiments were approved by local animal care committees (Behörde für Justiz und Verbraucherschutz der Freien und Hansestadt Hamburg; Lebensmittelsicherheit und Veterinärwesen, Hamburg, Germany).
Experiments were conducted in accordance with the Guide for the Care and Use of Laboratory Animals published by the US National Institutes of Health (publication No. 83-123, revised 1996). All procedures were performed in accordance with the ARRIVE guidelines (Animal Research: Reporting of In Vivo Experiments). The number of mice required for assessing statistical significance of pre-specified effects was estimated by power analysis based on preliminary results and previous experience with the models used in our laboratory [4].

10-18-week-old male C57BL/6 mice provided by the animal facility of the University Medical Center Hamburg-Eppendorf were studied. All mice were backcrossed on a C57BL/ 6 background for $>10$ generations. To evaluate effects on a global IL-10 deficiency and to perform bone-marrow transplantation we used $\mathrm{Il10}^{-/-}$mice and respective wild-type (WT) littermate controls. Subsets of Tregs were studied in male double reporter Foxp3IRES-mRFP $($ FIR $) \times I l 10-I R E S$-GFP-enhanced reporter (tiger) mice. To deplete the IL-10R on $\mathrm{CD} 4^{+}$, Foxp $3^{+}$, or $\gamma \delta \mathrm{T}$ cells we took advantage of the Cre-loxP system and crossed $C D 4^{C r e}, F o x p 3^{C r e}$, and TCR $\delta^{C r E R R}$ with Il10Ra $a^{f l / f l}$ mice, respectively. $C D 4^{\text {Cre }}$ [13], Foxp $3^{\text {Cre }}$ [14], Il10Ra ${ }^{f l f l}$ mice [15], FIR (Foxp3-IRES-mRFP) [16], and tiger (Il10-IRES-GFP-enhanced) [17] reporter mice were kindly provided by $\mathrm{S}$. Huber and are described elsewhere. $T C R \delta^{C r e E R}[18]$ mice were kindly provided by I. Prinz and are described elsewhere. For the induction of Cre-recombinase $T C R \delta^{C r e E R}$ animals were treated three times with $2 \mathrm{mg}$ Tamoxifen within 5 days at the age of 8-10 weeks. Two weeks later, the animals were used for experiments. CD $45.1^{+} \mathrm{WT}$ and $I l 10^{-/-}$mice were obtained from the Jackson Laboratory. For all animal experiments, mice were randomized and coded by an independent researcher to achieve blinding of the experiments. Agematched male WT littermates served as controls. To reduce the variability of our outcome parameters (neurological outcome, inflammatory response) caused by sex differences and to thereby decrease group sizes, only male mice were used throughout the study. Recent studies have demonstrated profound effects of sex-differences on infarct sizes and the inflammatory response. To validate our studies in females, further studies are required.

\section{Transient middle cerebral artery occlusion (tMCAO)}

We randomized all mice and conducted transient middle cerebral artery occlusion (tMCAO), using 6-0 nylon monofilament with silicone-coated tips (Doccol Corp.) as described previously [4]. Mice were anesthetized and monitored for heart rate, respiratory rate, oxygen saturation, and rectal body temperature. During filament-occlusion, cerebral blood flow was measured by laser-Doppler in the ipsi- and contralateral middle 
cerebral artery territory. Only mice with a reduction of $>80 \%$ in regional cerebral blood flow in the ipsilateral compared to the contralateral hemisphere were included. After $45 \mathrm{~min}$, the monofilament was retracted to allow reperfusion for 3,7 , or 14 days. In the sham group, carotid arteries were visualized without insertion of the filament. Following surgery, animals were kept on heating pads and sterile saline was given via subcutaneous injection for rehydration. Exclusion criteria were defined in a score, which included weight loss, general condition, spontaneous behavior, and impairment of wound healing. We anesthetized all mice (20 to $25 \mathrm{~g}, 12$ weeks; FTH, University Medical Center Hamburg-Eppendorf) using isoflurane $1 \%$ to $2 \% \mathrm{v} / \mathrm{v}$ oxygen. For analgesia we injected buprenorphine $0.03 \mathrm{mg} / \mathrm{kg} \mathrm{BW}$ intraperitoneally every $12 \mathrm{~h}$ for $24 \mathrm{~h}$. Mice were excluded from the study if they (i) died during the surgical procedure, (ii) experienced subarachnoid hemorrhage, (iii) had a Bederson score less than one after reawakening, or (iv) due to $<80 \%$ reduction in regional cerebral blood flow during MCAO.

\section{Antibody treatment}

Animals were treated intravenously with $500 \mu \mathrm{g}$ of mouse monoclonal anti-murine IL-17A antibody (Clone MM17F3; $16.6 \mathrm{mg} / \mathrm{kg}$ of body weight) or with $500 \mu \mathrm{g}$ of isotype-control antibody (IgG1, BioXCell, MOPC-21, BE0083) $3 \mathrm{~h}$ and 3 days after reperfusion.

\section{Intracerebroventricular injections}

Within $3 \mathrm{~h}$ after induction of MCA occlusion we performed an intracerebral injection of $200 \mathrm{ng}$ control vehicle [bovine serum albumin (BSA) in $2 \mu$ artificial cerebrospinal fluid consisting of mM: $126 \mathrm{NaCl} ; 2.5 \mathrm{KCl} ; 1.2$ $\mathrm{NaH}_{2} \mathrm{PO}_{4} ; 1.3 \mathrm{MgCl}_{2}$ and $2.4 \mathrm{CaCl}_{2}$ at $\left.\mathrm{pH} 7.4\right]$ or $200 \mathrm{ng}$ IL-10 [recombinant mouse protein (rmIL-10 (carrierfree), Biolegend \#575802) in $2 \mu \mathrm{l}$ artificial cerebrospinal fluid].

Intracerebral injections were performed as previously described [19]: briefly, mice were anesthetized with isoflurane (4\% for induction; $2.5 \%$ for maintenance) in $100 \%$ oxygen. The mice were placed in a stereotactic frame (Stoelting, 51500U) and a $1 \mathrm{~cm}$ long incision of the scalp was made over the midline. A cranial burr hole $(0.9 \mathrm{~mm})$ was drilled $2.2 \mathrm{~mm}$ lateral to the midline and $0.2 \mathrm{~mm}$ anterior to the bregma. A $10 \mu \mathrm{l}$ Hamilton syringe (Hamilton, 1701RN) was connected to a 26-gauge needle (Hamilton, 26G, Point Style 4, 12 $2^{\circ}$ ) and inserted into a motorized stereotaxic injector [Stoelting, integrated stereotaxic injector (ISI)]. The 26-gauge needle was then slowly introduced $3.7 \mathrm{~mm}$ deep into the left hemisphere and $2 \mu \mathrm{l}$ of IL-10 or control vehicle was infused at a rate of $0.5 \mu \mathrm{l} / \mathrm{min}$. The needle was left in place for another $10 \mathrm{~min}$ and then slowly withdrawn. Then a suture for the scalp incision was made. Animals recovered for a period of $60 \mathrm{~min}$ under a heating lamp with free access to food and water.

\section{Scoring}

Following stroke induction, we repeatedly scored mice using the Bederson score on a scale from $0-5$. This was done immediately after reawakening and every day until sacrifice. Bederson score: 0 no deficit, 1 preferential turning, 2 circlings, 3 longitudinal rollings, 4 no movement, 5 death. In addition, a composite neurological score was performed on 14 days after $\mathrm{tMCAO}$, adapted from Orsini et al. [20]: scores range from 0 (healthy) to 59 (the worst performance in all categories) and represent the sum of the results of all categories. These include general deficits: hair $(0-2)$, eyes $(0-3)$, ears $(0-2)$, posture $(0-3)$, spontaneous activity $(0-3)$, and focal deficits: circling $(0-5)$, gait $(0-4)$, body symmetry $(0-3)$, climbing on a surface held at $45^{\circ}(0-4)$, forelimb symmetry $(0-4)$, compulsory circling $(0-3)$, whisker response to a light touch (0-4), gripping (0-3), beam walking (0-9), balance on a beam $(0-3)$, and balance on a round stick $(0-4)$.

\section{Analysis of infarct size by triphenyltetrazolium chloride staining and magnetic resonance imaging (MRI)}

The infarct size was analyzed 7 days post-reperfusion by harvesting brains and cutting them into $1 \mathrm{~mm}$ slices (Braintree Scientific, $1 \mathrm{~mm}$ ) followed by vital staining using 2\% (wt/vol) 2,3,5-triphenyl-2-hydroxy-tetrazolium chloride in phosphate buffer. We determined infarct volumes in a blinded fashion using NIH ImageJ software.

MRI comprised T2-weighted imaging and was performed on a dedicated 7T MR small animal imaging system (ClinScan; Bruker) 3 and 14 day post-reperfusion.

\section{Bone-marrow chimeras}

For the generation of bone-marrow chimeras WT or $I l 10^{-/-}$mice were reconstituted with either $I l 10^{-/-}$or WT bone marrow, respectively. 6-8-week-old male recipients $\left(\mathrm{CD} 45.2^{+}\right)$were exposed to whole-body irradiation ( $9 \mathrm{~Gy} ; 1 \mathrm{~Gy} \mathrm{~min}^{-1}$ ) using a cesium-137 gamma irradiator (BIOBEAM 2000, Leipzig, Germany), as described before [21]. After $24 \mathrm{~h}$, mice were reconstituted with bone-marrow cells derived from tibiae and femurs from $\mathrm{CD} 45.2^{+} \mathrm{Il10^{-/- }}$ or CD $45.1^{+}$WT mice, respectively. Every recipient received $10^{7}$ bone-marrow cells intravenously. We assessed reconstitution and distribution between CD45.1 and CD45.2 cells by FACS analysis of peripheral blood cells of recipient mice 6 weeks after grafting. tMCAO was induced in recipient mice 6 weeks after transplantation. 


\section{Cell sorting}

Immune cells were sorted using a BD FACS Aria IIIu and collected in RPMI with $25 \%$ fetal calf serum.

\section{RNA isolation and quantitative real-time polymerase chain reaction}

We isolated RNA from brain tissue at indicated timepoints following tMCAO. Hemispheres were separated and homogenized in TRIzol Reagent $(1 \mathrm{ml}$ per $100 \mathrm{mg}$ tissue), chloroform was added, samples were centrifuged at $12,000 \times g$ for $15 \mathrm{~min}$ at $4{ }^{\circ} \mathrm{C}$ and the upper aqueous phase was collected. RNA was precipitated by the addition of isopropyl alcohol, washed and dissolved in TE-Buffer. We isolated total RNA from cells using QIA-Shredder spin columns and the RNeasy Micro Kit (QIAGEN) and transcribed complementary DNA using Maxima First Strand cDNA Synthesis Kit for RT-qPCR (Fermentas). Real-time PCR primers were obtained from Applied Biosystems (Carlsbad, CA): Il6: Mm00446190_ m1; Il23: Mm00518984_m1; Il1b: Mm00434228_m1; Tgfb: Mm01178820_m1; Cxcl1 Mm00433859_m1; Mmp3: Mm00442991_m1; BActin: Mm00607939_s1, Sdha: Mm01352366_m1. Probe mixtures were purchased from Fermentas (Waltham, MA). The relative gene expression was calculated using the $\Delta \Delta \mathrm{Ct}$ method and the samples were normalized to the control population and the expression of Sdha or $\beta$-Actin. Samples were randomized and coded by an independent researcher, so experiments were carried out blindly.

\section{Antibodies and flow cytometry}

Cell types were analyzed by flow cytometry, as previously described [4]. Briefly, mice were euthanized and perfused with phosphate-buffered saline. Only ipsilesional hemispheres were dissected, digested for $30 \mathrm{~min}$ at $37^{\circ} \mathrm{C}(1 \mathrm{mg} / \mathrm{ml}$ collagenase (Roche), $0.1 \mathrm{mg} / \mathrm{ml}$ DNAse I (Roche) in DMEM) and pressed through a cell strainer. Cells were incubated with standard erythrocyte lysis buffer on ice and separated from myelin and debris by Percoll gradient (GE Healthcare) centrifugation, followed by surface staining. In case of further intracellular staining $\mathrm{T}$ cells were stimulated with phorbol 12-myristate 13-acetate (100 ng/ml; Sigma-Aldrich) and ionomycin $(1 \mu \mathrm{g} / \mathrm{ml}$; Sigma-Aldrich) in the presence of brefeldin A ( $3 \mu \mathrm{g} / \mathrm{ml}$; eBioscience) at $37{ }^{\circ} \mathrm{C}$ in $10 \% \mathrm{CO}_{2}$ for $4 \mathrm{~h}$ before surface staining. To achieve fixation, permeabilization and intracellular staining True-Nuclear ${ }^{\mathrm{TM}}$ Transcription Factor Buffer Set (Biolegend, \#424401) was used according to the manufacturer's instructions. Mouse antibodies were as follows: from Biolegend CD45.2 (104; \#109805), CD45.1 (A20, \#110707), B220 (RA3-6B2, \#103245, \#103237), CD3 (145-2C11, \#100308; 17A2,
\#100228), NK1.1 (PK136, \#108745, \#108713), TCR- $\gamma \delta$ (GL-3, \#118118), CD4 (RM4-5, \#100553, \#100551), CD8 (53.6-7, \#100732, \#100741, \#100722), CD49b (HM 2 2, \#103506), CD11b (M1/70, \#101216), MHC II (M5/ 114.15.2; \#107605), Ly6g (1 A8; \#127627), F4/80 (BM8, \# 123133), Lag-3 (C9B7W, \#125210), PD-1 (29F.1A12, \#135220), IFN- $\gamma$ (XMG1.2, \#505815, \#505839), CD210 (1B1.3a, \#112705); from eBioscience CD45 (30-F11, \#470451-82, \#56-0451-82), CD19 (eBio1D3, \#25-0193-81), CD11c (N 418, \#25-0114-82), TIGIT (GIGD7, \#46-950182) and IL-17A (eBio17B1, \#17-7177-81); from BD Bioscience CD4 (GK1.5, \#563790) and RORYT (Q31-378, \#562607). TruCount tubes (BD Bioscience), containing fluorescence beads were used to determine the total cell counts per hemisphere to compare the absolute number of IL-17A ${ }^{+}$infiltrating $\mathrm{CD}^{+}$and $\gamma \delta \mathrm{T}$ cells and neutrophils in $I l 10^{-/-}$vs. WT mice according to the manufacturer's protocol. $30 \%$ of each sample volume was used for an isotype control. Data were acquired with a Fortessa FACS system (BD Biosciences) and analyzed with FlowJo. Doublets were excluded with FSC-A and FSC-H linearity.

\section{Immunohistochemistry and immunofluorescence}

Immunofluorescence stainings for GFP and CD45 coexpressing cells were performed on $20 \mu \mathrm{m}$ thick fresh frozen brain sections as previously described [22]. Cryostat cut sections were air-dried, rinsed in TBS for 10 min before blocked with $10 \%$ fetal calf serum in TBS $+0.5 \%$ Triton for 30 min at RT. Next, sections were incubated with rabbit anti-mouse GFP (ab290, Abcam) overnight at $4{ }^{\circ} \mathrm{C}$. The following day the sections were rinsed for $10 \mathrm{~min}$ in TBS $+0.5 \%$ Triton before incubation with the cross-absorbed species-specific secondary antibody Alexa Flour 488 goat anti-rabbit (\#A11070, Invitrogen) diluted 1:200 for $2 \mathrm{~h}$. Next, the sections were rinsed in TBS for $10 \mathrm{~min}$ before incubation for $2 \mathrm{~h}$ with PE-conjugated rat anti-mouse CD45 (\#553081 BD Biosciences). After a $2 \times 10 \mathrm{~min}$ rinse in TBS the sections were transferred to TBS containing 40,6-diamidino-2-phenylindole (DAPI) (D1306, Invitrogen), rinsed in water, and mounted in gelvatol. Respective isotype controls were devoid of signal.

\section{Statistical analysis}

Statistical analyses were performed using the appropriate test indicated in the figure legends. Briefly, the Student $t$ test was used to compare infarct volumes, the MannWhitney $U$ test for the comparison of clinical scores, and the one-way ANOVA test for multiple comparisons with the Bonferroni post hoc test. $P$ values $<0.05$ were considered statistically significant. 


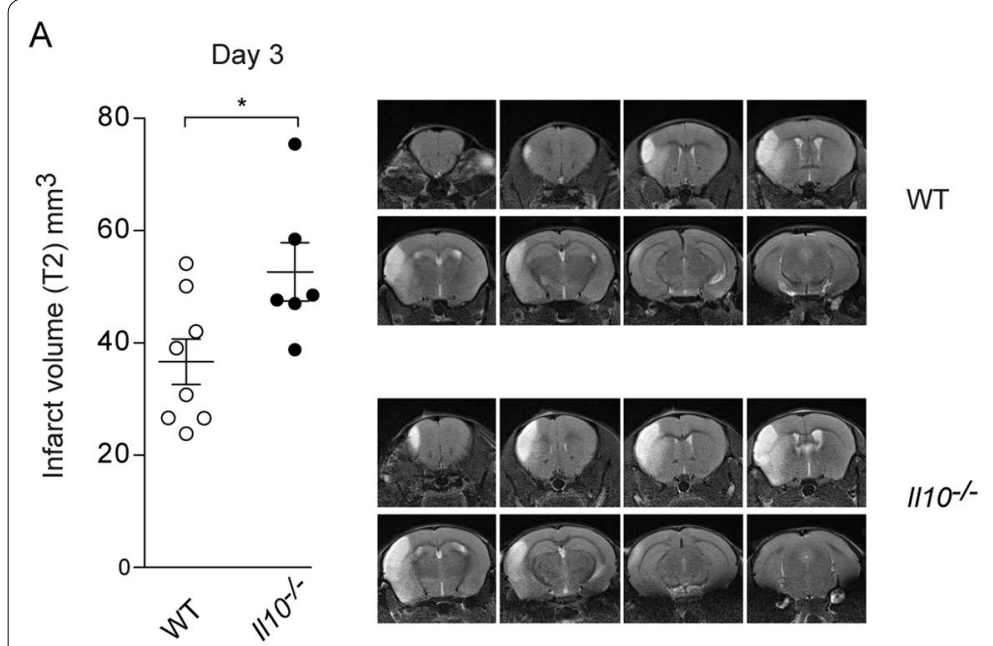

C

Day 14
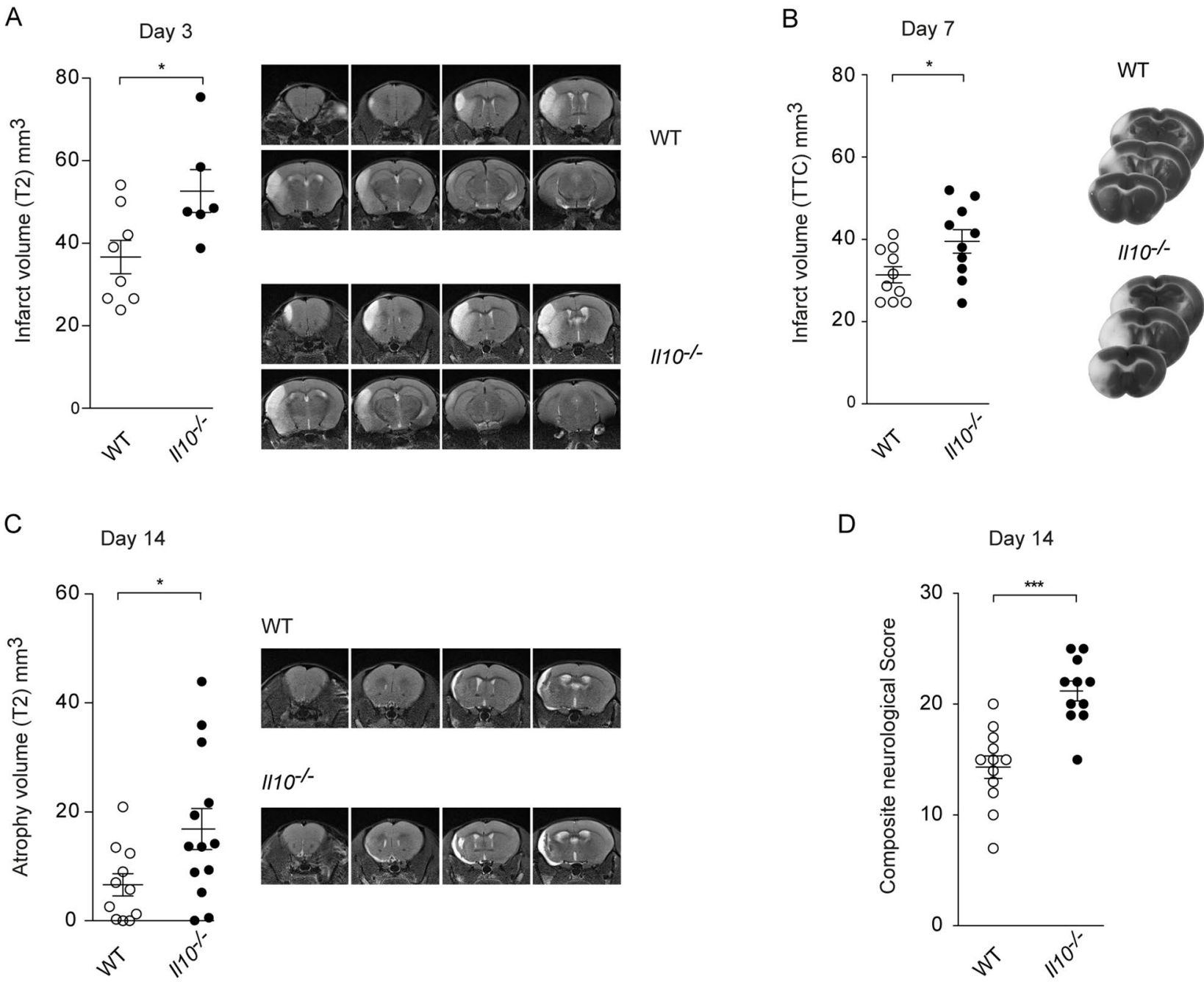

WT

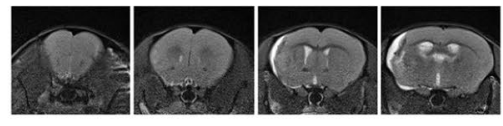

$1110^{-/-}$

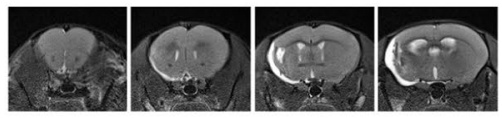

D

Day 14

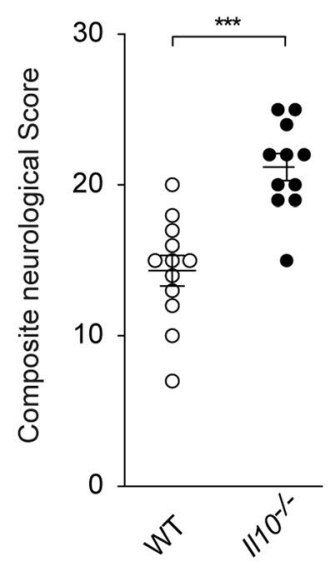

$E$

Day 14
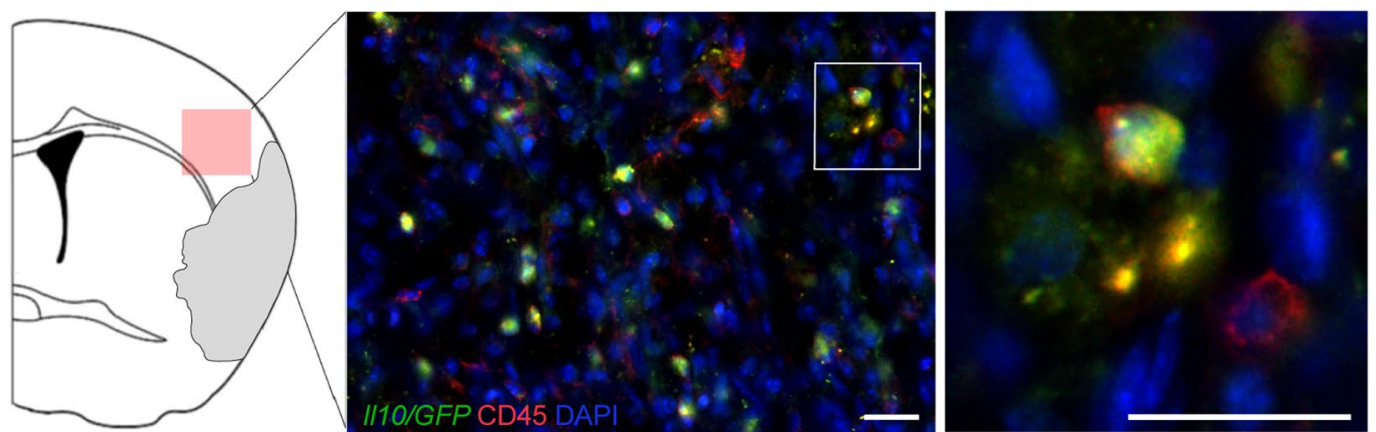

Fig. 1 //10 deficiency leads to increased infarct sizes, enhanced brain atrophy, and poorer long-term outcome following tMCAO. MRI was used to quantify infarct volume at day $3(\mathbf{A})$ and cortical atrophy volume at day 14 (C) after IMCAO in WT control and $/ 110^{-/-}$mice (representative T2 image). B Triphenyltetrazolium chloride (TTC) staining was used for the evaluation of infarct volume at day 7 (representative TTC brain slices). D Composite neurological score was performed on day 14 after tMCAO. E //10/GFP-positive cells were visualized in the penumbra area of the ischemic hemisphere by GFP counterstaining in FIR-tiger mice 14 days after IMCAO (green, I/10/GFP-positive cells; red, CD45-positive cells; blue, 40,6-diamidino-2-phenylindole nuclear staining; scale bar $20 \mu \mathrm{m})$. Infarct data are presented as mean \pm SEM of 8-10 WT and 6-10 //10-/- mice (A B), atrophy data as mean \pm SEM of $11 \mathrm{WT}$ and $13 / 110^{-/-}$mice $(\mathbf{C})$, and neurological score of $12 \mathrm{WT}$ and $11 / 110^{-/-}$mice (D). Statistical significances were analyzed by Student $t$ test $(\mathbf{A}-\mathbf{C})$ and Mann-Whitney $U$ test $(\mathbf{D}) .{ }^{*} P<0.05$ and ${ }^{* * *} P<0.001$ 


\section{Results}

\section{IL-10 is protective following transient middle cerebral artery occlusion in mice}

To investigate the role of IL-10 in acute ischemic brain damage and the subsequent recovery, we analyzed the neurological outcomes of Interleukin-10 knockout $\left(I l 10^{-/-}\right)$mice and wild type (WT) littermate controls up to 14 days after tMCAO. On day 3 and day $7 \mathrm{Il10}^{-/-}$mice exhibited significantly increased infarct volumes (Fig. 1A, B). Underlining the impact of IL-10 not only on the initial damage but also on the regeneration we found that $I l 10^{-1-}$ mice showed significantly increased brain atrophy and worse neurological scores on day 14 when compared to littermate controls (Fig. 1C, D, and Additional file 1: Fig. S1A). Mortality did not differ significantly between groups (Additional file 1: Fig. S1B).

\section{IL-10 is upregulated in infiltrating T cells and macrophages} To visualize the spatial distribution and cellular source of IL-10 in post-stroke brains, we performed immunohistochemistry using a reporter mouse expressing a green fluorescent protein (GFP) under the control of the IL-10 promotor. Fourteen days following tMCAO, we detected GFP-positive CD $45^{+}$cells in the penumbra area of the infarct indicating that immune cells contribute to the local IL-10 production in ischemic brains (Fig. 1E).

Next, we studied whether the IL-10 production from invading immune cells or brain resident cells including microglia, astrocytes, or neurons is decisive for the protective IL-10 effect following stroke. We generated bonemarrow chimeric mice using CD $45.1^{+} \mathrm{WT}$ or CD $45.2^{+}$ $I l 10^{-/-}$donor mice which were injected into CD $45.2^{+}$ $I l 10^{-/-}$or $\mathrm{WT}$ recipient mice, respectively. Following reconstitution $>98 \%$ leukocytes expressed congenic markers of the respective donor (Additional file 1: Fig. S2A, B). On day 3 after tMCAO we observed that $I l 10^{-/-}$ mice reconstituted with WT bone-marrow displayed significantly reduced infarct volumes when compared to WT littermate controls reconstituted with $1 l 10^{-/-}$bonemarrow cells. Underscoring the importance of IL-10 from peripheral immune cells, we further found that Ill1 ${ }^{-/-}$mice reconstituted with WT bone-marrow displayed significantly improved neurological scores 14 days post-stroke, whereas brain atrophy did not differ significantly between groups (Fig. 2A-C).

To further investigate the temporal dynamics and the cellular source of IL-10, we measured mRNA levels of Il10 transcripts in CD $45^{\text {intermediate }}, \mathrm{CD} 11 \mathrm{~b}^{\text {high }}$ microglia and $C D 45^{\text {high }}, \mathrm{CD} 11 \mathrm{~b}^{\text {high }}$, Ly6g $\mathrm{g}^{\text {negative }}$ macrophages on days 3,7 , and 14 post-stroke. Although contamination of macrophages with activated microglia is possible in this sorting strategy, it allows an estimation of IL-10 expression levels in both populations (Fig. 2D). Notably, macrophages showed significantly increased IL-10 level on days 7 and 14, whereas microglia showed a significant upregulation only on day 14, suggesting that the IL-10 production of macrophages and microglia is delayed following ischemia (Fig. 2D).

Besides microglia and macrophages, lymphocytes are an important source of IL-10. As the staining of IL-10 by hand is challenging we took advantage of the doubleknock-in reporter Fir-tiger mouse model, which enables the simultaneous detection of IL-10 [green fluorescent protein (GFP)] and Foxp3 [monomeric red fluorescent protein (mRFP)] by flow cytometry. $\mathrm{CD} 4^{+} \mathrm{T}$ cells exhibited the highest frequency of IL-10 producers when compared to $\mathrm{B}$ and NK cells as well as $\mathrm{CD}^{+} \mathrm{T}$ cells (Additional file 1: Fig. S2C) [23]. Interestingly, in $\mathrm{CD}^{+}$ $\mathrm{T}$ cells, we identified two different $\mathrm{IL}-10^{+}$subpopulations that peak at different timepoints following stroke. On day 3 following tMCAO, IL- $10^{+}$Foxp $3^{-}$CD $4^{+} \mathrm{T}$ cells were significantly increased in frequency compared to sham surgery. Notably, these $\mathrm{CD}^{+} \mathrm{T}$ cells did not coexpress the $\mathrm{T}_{\mathrm{r}} 1$ cell markers CD49b and Lag-3, while $\mathrm{T}_{\mathrm{r}} 1$ cells were detectable at the same timepoint in spleens of respective mice (Additional file 1: Fig. S2D) [23]. On day 7 , the IL- $10^{+}$Foxp $3^{-} \mathrm{CD}^{+} \mathrm{T}$ cells decreased in frequency, while IL- $10^{+}$Foxp $3^{+}$Tregs appeared in ischemic hemispheres reaching significance on day 14 when compared to sham surgery (Fig. 2E).

Combined, this data suggests that the IL-10 production of infiltrating immune cells, in particular T cells and

\footnotetext{
(See figure on next page.)

Fig. 2 IL-10 from invading immune cells is neuroprotective. MRI was used to quantify infarct volume at day 3 and cortical atrophy volume at day $14(\mathbf{A}, \mathbf{B})$ after tMCAO in the chimeric mice (representative T2 image). C Composite neurological score was performed on day 14 after tMCAO. D Relative gene expression of $/ 110$ in brain resident CD $45^{\text {intermed }} / C D 11 b^{+}$microglia and central nervous system-infiltrating CD $45^{\text {high }} / \mathrm{CD} 11 \mathrm{~b}^{+} / \mathrm{CD} 11 \mathrm{c}^{-} /$ $\mathrm{MHCII}^{-} / \mathrm{Ly} 6 \mathrm{~g}^{-} / \mathrm{F} 4 / 80^{+}$macrophages purified 3,7 , and 14 days after $\mathrm{MCAO}$ by fluorescence activated cell sorting from ischemic hemispheres of C57Bl/6 mice. Expression levels were normalized to corresponding levels of microglia after sham surgery or blood macrophages. E Flow cytometric analysis of IL-10 produced by CD4 ${ }^{+}$Tregs $\left(\right.$Foxp3 ${ }^{+}$) or non-Tregs (Foxp3 ${ }^{-}$). Infarct and atrophy data are presented as mean \pm SEM of 16 WT mice which received $/ 110^{-/-}$and $10-11 / 110^{-/-}$mice which received WT bone-marrow cells $(\mathbf{A}, \mathbf{B})$, neurological score as mean \pm SEM of 15 WT mice which received $/ 110^{-/-}$and $10 / / 10^{-/-}$mice which received WT bone-marrow cells (C), RT-qPCR gene expression data as mean \pm SEM of 3-7 (D) and flow cytometric data as mean of \pm SEM of 5-10 mice in each group (E). Significances analyzed by Student $t$ test $(\mathbf{A}, \mathbf{B})$, Mann-Whitney $U$ test $(\mathbf{C})$, and 1-way ANOVA with Bonferroni post hoc test (D, E). ${ }^{*} P<0.05$, ${ }^{* *} P<0.01,{ }^{* * *} P<0.01$ and ${ }^{* * * *} P<0.0001$. MФ macrophages, MG microglia
} 


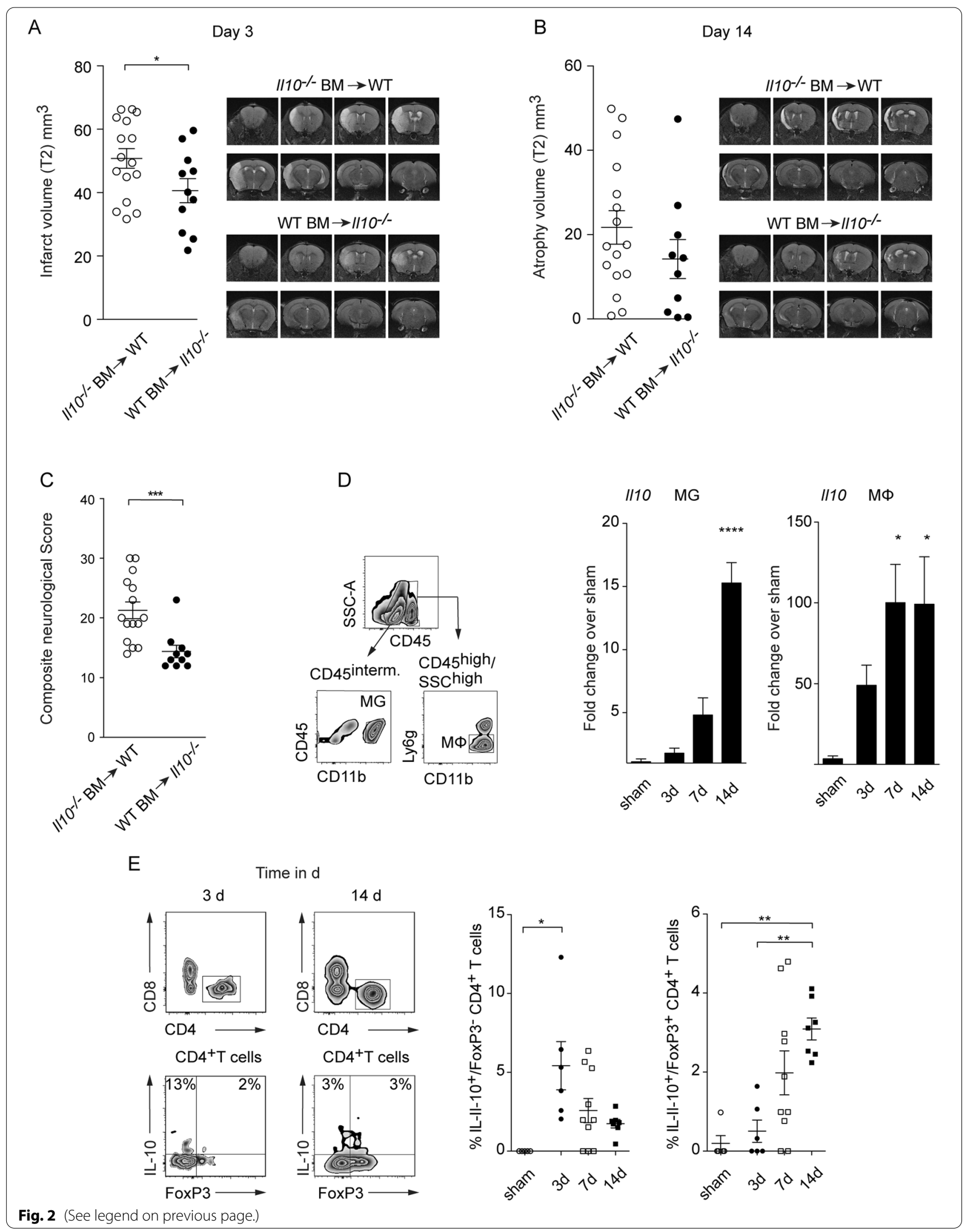


macrophages, is decisive for IL-10-mediated neuroprotection in stroke.

\section{IL-10 controls the IL-17A response in the inflamed brain}

In models of autoimmunity including inflammatory bowel disease [8] or nephritis [9], IL-10 effects largely depend on the inhibition of IL-17A pathways. IL-17A-dependent inflammatory pathologies in turn are induced by the prototypical pro-inflammatory cytokines IL-1 $\beta$ and IL-23 among others. To investigate whether IL-1 $\beta$ and IL-23 are also upregulated following ischemia, we investigated their expression in microglia and macrophages sorted from ischemic hemispheres. In microglia, we observed a significant increase in $I l 23 a$ and $I l 1 b$ mRNA levels on day 14 (Fig. 3A). Macrophages showed a significant upregulation of $I l 23 a$ and $I l 1 b$ on day 7 and of $I l 1 b$ on day 14, respectively (Fig. $3 \mathrm{~B}$ ). Overall, these results demonstrate a sustained upregulation of IL-17A-polarizing cytokines in the ischemic brain.

To investigate whether IL-10 is capable to control IL$17 \mathrm{~A}$ pathways in the presence of IL- $1 \beta$ and IL-23, we next analyzed IL-17A level in $\alpha \beta$ and $\gamma \delta$ T cells from ischemic brains of $1 l 10^{-/-}$and WT mice. On day 7, we observed a significant increase in frequency and absolute counts of $\mathrm{IL}_{-17 \mathrm{~A}^{+} \mathrm{CD}^{+}}{ }^{+}$and $\mathrm{IL}-17 \mathrm{~A}^{+} \gamma \delta \mathrm{T}$ cells in the postischemic CNS of $1 l 10^{-1-}$ mice when compared to WT littermate controls (Fig. 3C, and Additional file 1: Fig. S3A). Notably, in contrast to IL-17A positive $\gamma \delta \mathrm{T}$ cells, we detected almost no Th17 cells on day 7 in WT littermates, indicating that physiological IL-10 levels strictly suppress the IL-17A production in $\mathrm{CD} 4^{+} \mathrm{T}$ cells in ischemic brains.

The main IL-17A effect in the ischemic brain is the induction of neutrophil-attracting chemokines (e.g., CXCL-1) [4, 24] as well as Matrix Metalloproteinases [4, 25]. Consistent with increased IL-17A levels, we detected a significant upregulation of $\mathrm{Cxcl} 1$ and $\mathrm{Mmp} 3$ transcripts in the whole brain mRNA and a significant increase in absolute numbers of neutrophils at day 3 post-stroke in $\mathrm{IllO}^{-/-}$mice, respectively (Fig. 3D, and Additional file 1: Fig. S3B).
Next, we performed intracerebral injections of $200 \mathrm{ng}$ recombinant IL-10 or Bovine Serum Albumin (BSA) in WT mice $3 \mathrm{~h}$ following tMCAO to evaluate the capacity of IL-10 to suppress IL-17A production locally in the ischemic brain. Intracerebral IL-10 treatment significantly lowered the presence of IL-17A producing $\gamma \delta$ $\mathrm{T}$ cells when compared to a BSA control 3 days posttMCAO (Fig. 3E).

To show that the dysregulation of IL-17A is decisive for the worse outcome in $I l 10^{-/-}$mice, we treated $I l 10^{-/-}$mice and littermate controls with $500 \mu \mathrm{g}$ IL-17A neutralizing antibody or IgG control $3 \mathrm{~h}$ and 3 days posttMCAO. Anti-IL17A treatment rendered the infarct volume and the neurological scores of $I l 10^{-/-}$and WT littermate controls almost equal 7 days post-tMCAO (Fig. 4A, B). Importantly, treatment with the IgG control antibody did not rescue the worse outcome of $\mathrm{IllO}^{-/-}$ when compared to littermate controls (Fig. 4C, D).

\section{Differential effects of IL-10 on IL-17A+ brain infiltrating $C D 4^{+}$ and $\gamma \delta T$ cells}

To identify whether IL-10 directly inhibits the IL-17A response through the IL-10 receptor on T cells, we next employed transgenic mice, in which the IL-10 signaling is abrogated in mature $\mathrm{CD} 4^{+} \mathrm{T}$ cells. To generate a deletion of the $\alpha$-chain of the IL-10R in $\mathrm{CD} 4^{+} \mathrm{T}$ cells which is essential for IL-10 signaling, we bred $C D 4^{\text {Cre }}$ with IlloRa $a^{f l f l}$ mice. We observed a significant increase in frequency of IL- $17 \mathrm{~A}^{+}$brain-infiltrating $\mathrm{CD} 4^{+}$and $\gamma \delta$ T cells of $C D 4^{C r e} \times I l 10 R a^{f l / f l}$ mice at day 7 following tMCAO when compared to $C D 4^{C r e} \times I l 10 R a^{w t / w t}$ control mice (Fig. 5A, B). As $\gamma \delta \mathrm{T}$ cells from $C D 4^{C r e} \times I l 10 R a^{f l f l}$ mice have an intact IL-10 receptor, these data suggest that $\gamma \delta$ $\mathrm{T}$ cells are inhibited through alternative pathways which are indirectly controlled by IL-10, whereas IL-10 exerts its inhibitory functions directly on $\mathrm{CD} 4^{+} \mathrm{T}$ cells.

Notably, IL- $17 \mathrm{~A}^{+} \gamma \delta \mathrm{T}$ cells display a significantly lower IL-10R expression when compared to IL-17A ${ }^{-} \gamma \delta$ T cells. This finding further supports the hypothesis that IL-17A $\mathrm{A}^{+}$ $\gamma \delta$ T cells are not directly inhibited by IL-10 (Fig. 5C).

(See figure on next page.)

Fig. 3 IL-10 controls the IL-17A axis in the proinflammatory milieu of the postischemic brain. Relative gene expression of $1 / 23 a$ and $/ 11 b$ in brain resident $\mathrm{CD} 45^{\text {intermed }} / \mathrm{CD} 11 \mathrm{~b}^{+}$microglia (A) and central nervous system-infiltrating CD $45^{\text {high }} / \mathrm{CD} 11 \mathrm{~b}^{+} / \mathrm{CD} 11 \mathrm{c}^{-} / \mathrm{MHCll}^{-} / \mathrm{Ly} 6 \mathrm{~g}^{-} / \mathrm{F} 4 / 80^{+}$macrophages (B) purified 3,7 and 14 days after tMCAO by fluorescence activated cell sorting from ischemic hemispheres. Expression levels were normalized to corresponding levels of splenic macrophages and microglia after sham operation. C Flow cytometric analysis of IL-17A produced by CD4+ and $\gamma \delta \mathrm{T}$ cells isolated from ischemic hemispheres of WT controls and $/ 110^{-/-}$mice 7 days after tMCAO. D Flow cytometric analysis of number of infiltrating neutrophils in the ischemic hemispheres of WT controls and $/ 110^{-/-}$mice 3 days after tMCAO. E Frequency of IL-17A producing $\gamma \delta \mathrm{T}$ cells purified from ischemic brains was analyzed 3 days following tMCAO in control mice (BSA) and mice receiving $I L-10$ intracerebral $3 \mathrm{~h}$ after tMCAO induction. A, B RT-qPCR gene expression data is represented as mean \pm SEM of 4-7 WT, Flow cytometric data as mean \pm SEM of 6 WT and $5 / 10^{-/-}$(C), 9 WT and $7 / 110^{-1-}$ mice (D), and of 7 WT mice in each treatment group (E). Statistical significances were analyzed by one-way ANOVA with Bonferroni post hoc test $(\mathbf{A}, \mathbf{B})$ and by Student $t$ test $(\mathbf{C}-\mathbf{E}) .{ }^{*} P<0.05,{ }^{* *} P<0.01,{ }^{* * *} P<0.001,{ }^{* * *} P<0.0001$ 


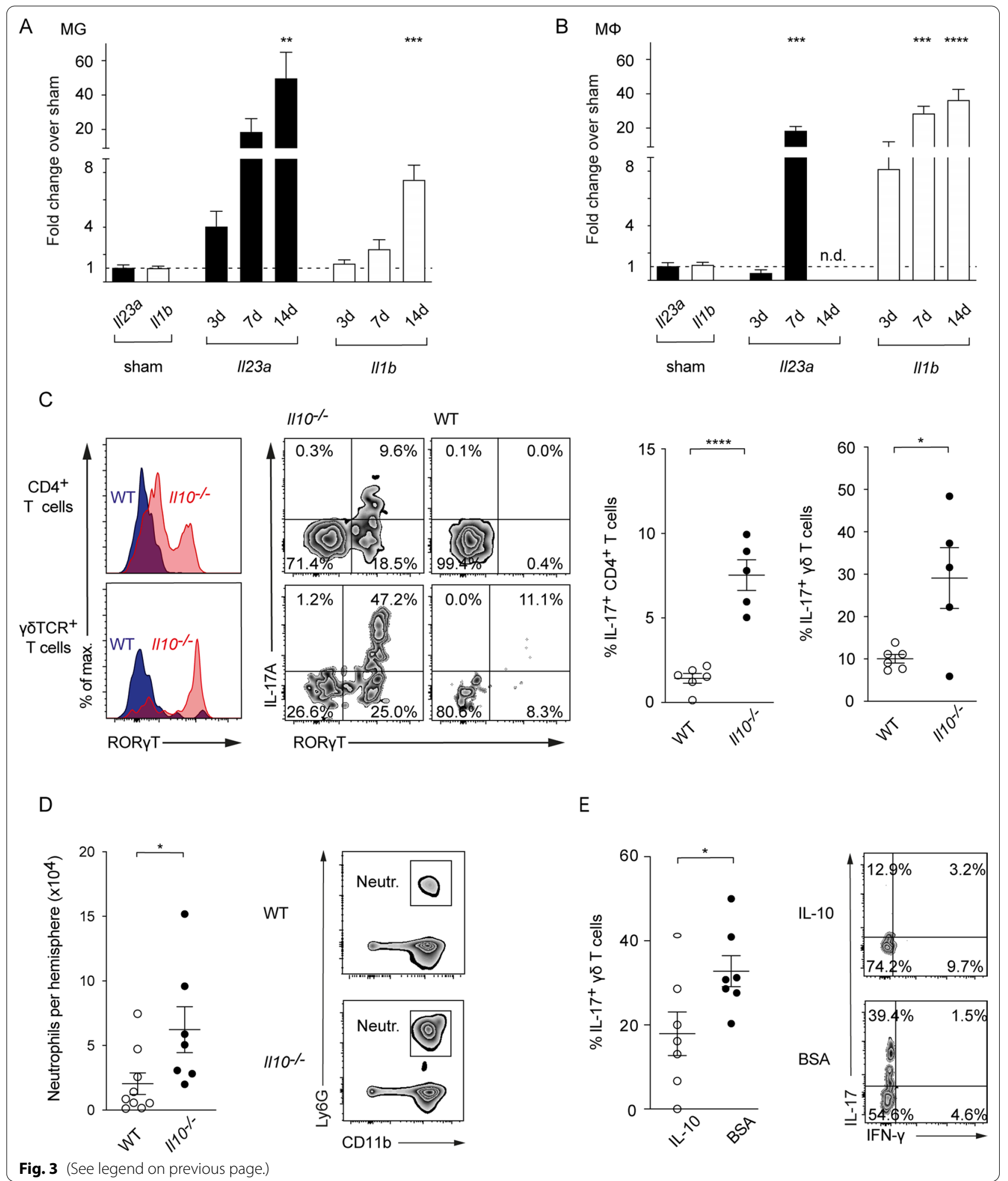

To confirm that IL-10 is not affecting $\gamma \delta \mathrm{T}$ cells directly, we bred $T C R \delta^{C r e E R} \times I l 10 R a^{f l f l}$ mice. In line with our finding in $C D 4^{C r e} \times I l 10 R a^{f l f l}$ mice, the selective depletion of the IL-10 receptor in $\gamma \delta$ T cells had no direct effect on their IL-17A production (Fig. 5D). 
In sum, these data suggest that CD4 $\mathrm{T}$ cells play a central role for the control of the detrimental IL-17A response in ischemic brains, and that the IL-10 signaling in CD4 T cells is essential for their protective function. That the targeted depletion of the IL-10 receptor on $\gamma \delta$ $\mathrm{T}$ cells does not alter their IL-17A production, in turn, clearly indicates that the IL-17A production in these innate lymphocytes is not directly controlled by IL- 10 .

\section{IL-10R expression on Tregs is obligatory to inhibit IL-17A production in $\gamma \delta \mathrm{T}$ cells}

To further investigate whether Treg or non-Treg CD4 T cells are capable to react to IL-10 and thus potentially control $\gamma \delta \mathrm{T}$ cells, we next analyzed expression levels of the IL-10 receptor in double reporter Fir-tiger mice. On day 7 following tMCAO, we observed a significantly higher expression of the IL-10 receptor in the Foxp $3^{+}$ compared to the Foxp3 $3^{-}$compartment (Fig. 6A), further supporting that IL-10 can activate Tregs.

To further test whether Tregs are controlling $\gamma \delta \mathrm{T}$ cells in ischemic brains and if IL-10 confers Tregs the ability to inhibit the IL-17A production in $\gamma \delta \mathrm{T}$ cells, we bred Foxp $3^{C r e} \times I l 10 R a^{f l / f l}$ mice to generate a Tregselective deletion of the IL-10R $\alpha$. Seven days following $\mathrm{tMCAO}$, we analyzed the frequency of $\mathrm{IL}^{-17 \mathrm{~A}^{+}}$ CD4 and $\gamma \delta \mathrm{T}$ cells derived from ischemic hemispheres (Fig. 6B, C). Upon deletion of the IL-10R $\alpha$ in Tregs, $\mathrm{CD}^{+} \mathrm{T}$ cells displayed no skewing towards a Th17 phenotype. However, we observed a significantly increased IL-17A production in $\gamma \delta \mathrm{T}$ cells in Foxp $3^{C r e} \times I l 10 R a^{f l / f l}$ mice (Fig. 6C).

It has been reported that programmed cell death protein 1 (PD-1) negatively regulates IL-17A levels in $\gamma \delta \mathrm{T}$ cells in a model of psoriatic-like skin inflammation [26]. To estimate the potential function of PD-1 in the control of IL-17A in $\gamma \delta \mathrm{T}$ cells in stroke, we analyzed PD-1 levels in $\gamma \delta \mathrm{T}$ cells from ischemic hemispheres and cervical lymph nodes. In line with a PD-1-dependent control of IL-17A ${ }^{+} \gamma \delta$ T cells we found a significantly increased frequency of PD-1/IL-17A double positive $\gamma \delta \mathrm{T}$ cells from ischemic hemispheres, when compared to PD-1/IL-17A positive $\gamma \delta$ T cells from cervical lymph nodes (Additional file 1: Fig. S3C).
In summary, our data show that IL-10, which by itself had no direct effect on $\gamma \delta$ T cells, is able to suppress the IL-17A production of $\gamma \delta$ T cells via Tregs.

\section{Discussion}

IL-17A is seen as a decisive factor for the early detrimental postischemic inflammatory response following stroke $[3,4]$. One of the main effects of the IL-17A axis in ischemic brains is the induction of $\mathrm{CXC}$-chemokines, which lead to a massive infiltration of neutrophils [4, 24]. However, in stroke, the initial IL-17A driven inflammatory response is short-lasting, indicating that the sterile inflammatory response is effectively controlled [4].

Mechanisms that limit the detrimental IL-17A response in stroke are not well understood. In this study, we tested whether the anti-inflammatory cytokine IL-10 controls the early IL-17A response in $\mathrm{T}$ cells following experimental stroke. We found that IL-10 expressed by invading leukocytes plays a key role in the regulation of the IL-17A production in both $\alpha \beta$ and $\gamma \delta \mathrm{T}$ cells in ischemic hemispheres. Interestingly, the effects of IL-10 on $\mathrm{CD}^{+}$and $\gamma \delta \mathrm{T}$ cells differ. While IL-10 directly inhibits the IL-17A production in $\mathrm{CD} 4^{+} \mathrm{T}$ cells, signaling via the IL-10R endows Tregs with the capacity to downregulate IL-17A in $\gamma \delta \mathrm{T}$ cells. However, abrogation of direct IL-10R signaling in $\gamma \delta \mathrm{T}$ cells does not impact their IL$17 \mathrm{~A}$ production, underlining that IL-10 controls the IL17A production of $\alpha \beta$ and $\gamma \delta$ T cells differentially.

As a source of IL-10 we did not only identify Foxp $3^{+}$ Tregs, macrophages and microglia in ischemic brains, but also Foxp3 ${ }^{-} \mathrm{CD}^{+} \mathrm{T}$ cells. Interestingly, these IL- $10^{+} /$Foxp $^{-} / \mathrm{CD}{ }^{+} \mathrm{T}$ cells were negative for CD49d and Lag-3, indicating that these are not $\mathrm{T}_{\mathrm{r}} 1$ cells. Given the plasticity of $\mathrm{T}$ cells under inflammatory conditions, it is possible that the Foxp3 $3^{-} / \mathrm{CD}^{+} / \mathrm{IL}_{-}-10^{+} \mathrm{T}$ cells are $\mathrm{T}_{\mathrm{h}} 1$ [27], $\mathrm{T}_{\mathrm{h}} 2$ [28] or even $\mathrm{T}_{\mathrm{h}} 17$ [29] cells that participate in the resolution of inflammation.

Furthermore, it should be considered that other infiltrating immune cells and resident cells such as B cells [30] and astrocytes [31] are additional sources of IL-10, which endow Tregs to control the IL-17A production in $\gamma \delta \mathrm{T}$ cells. The role of IL-10 from brain resident cells is supported by our data from bone-marrow chimeric mice. Although bone-marrow chimeras with an IL-10-deficient peripheral immune compartment displayed significantly

(See figure on next page.)

Fig. 4 Neutralization of IL-17A abolishes the worse outcome of $/ 110^{-/-}$mice. Triphenyltetrazolium chloride staining was used for evaluation of infarct volume at day 7 of IL-17A antibody (A) or IgG control (C) treated $/ 110^{-/-}$and WT control mice. Bederson score was performed 7 days after tMCAO IL-17A antibody (B) or in IgG control (D) treated group. Infarct data are presented as mean \pm SEM of 9-11 WT and 6-9 $/ / 10^{-/-}$mice per group. Bederson score as mean \pm SEM of 9-11 WT and 7-10 $/ 110^{-/-}$mice per group. Statistical significances were analyzed by Student $t$ test $(\mathbf{A}, \mathbf{C})$ and Mann-Whitney $U$ test $(\mathbf{B}, \mathbf{D}) .{ }^{*} P<0.05$ 


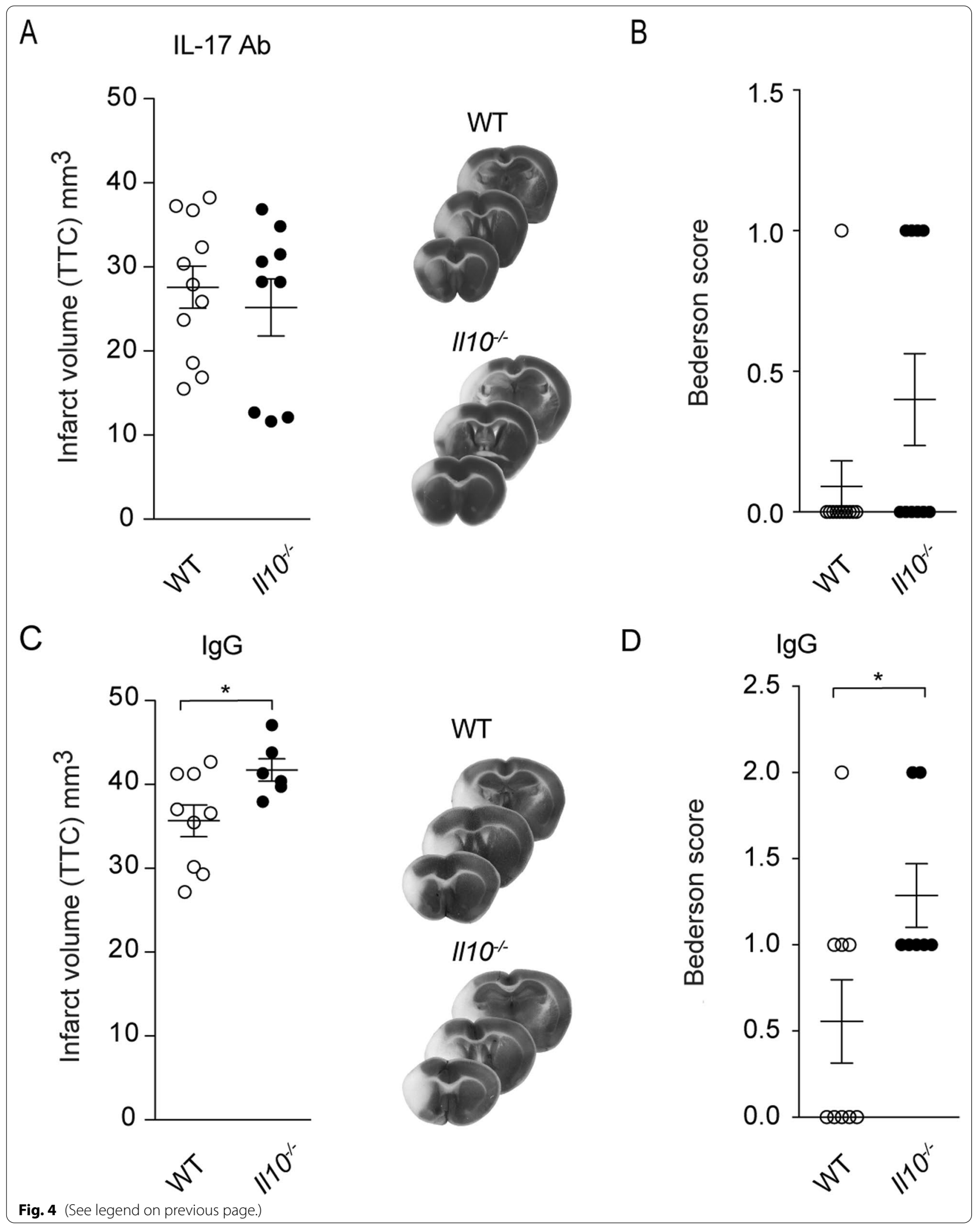




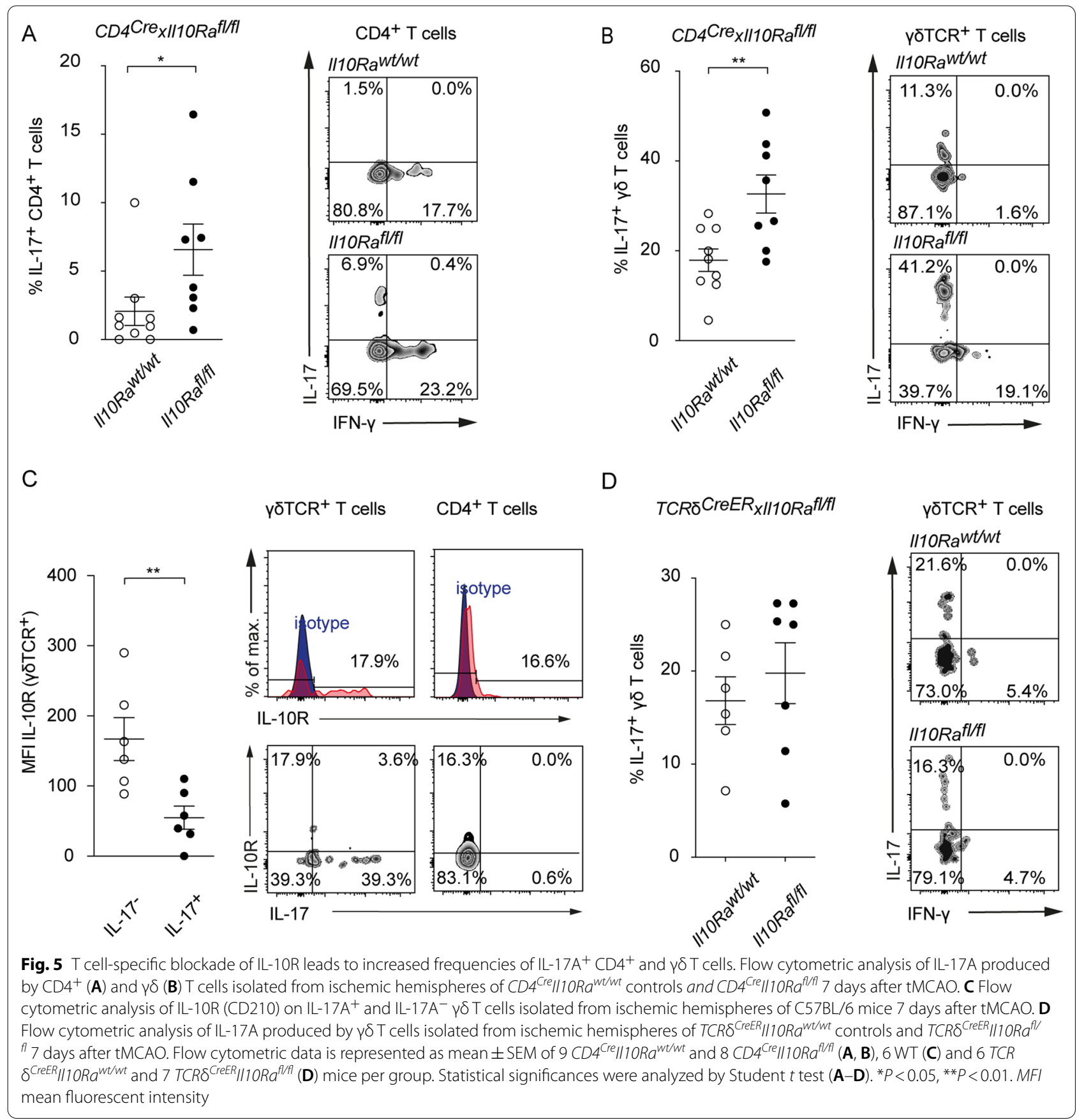

larger infarcts at 3 days following tMCAO, when compared to bone-marrow chimeras with an IL-10-deficiency in brain resident cells, brain atrophy was not significantly altered at 14 days between both groups. This observation indicates that IL-10 from peripheral immune cells is involved in the control of the initial damaging inflammatory response, whereas IL-10 from resident brain cells might have trophic functions during regeneration.
IL-10 has been implicated in several studies to provide neuroprotection in the brain $[6,32]$. However, in stroke, only Benakis et al. found that IL-10 is protective through the control of IL-17A pathways [24]. The authors showed that the modulation of the gut microbiome diminished the frequency of IL-17A $\mathrm{A}^{+} \gamma \delta \mathrm{T}$ cells in the gut in an IL10-dependent manner which was associated with an attenuation of the IL-17A driven postischemic inflammatory reaction in the brain. Beyond these observations, 


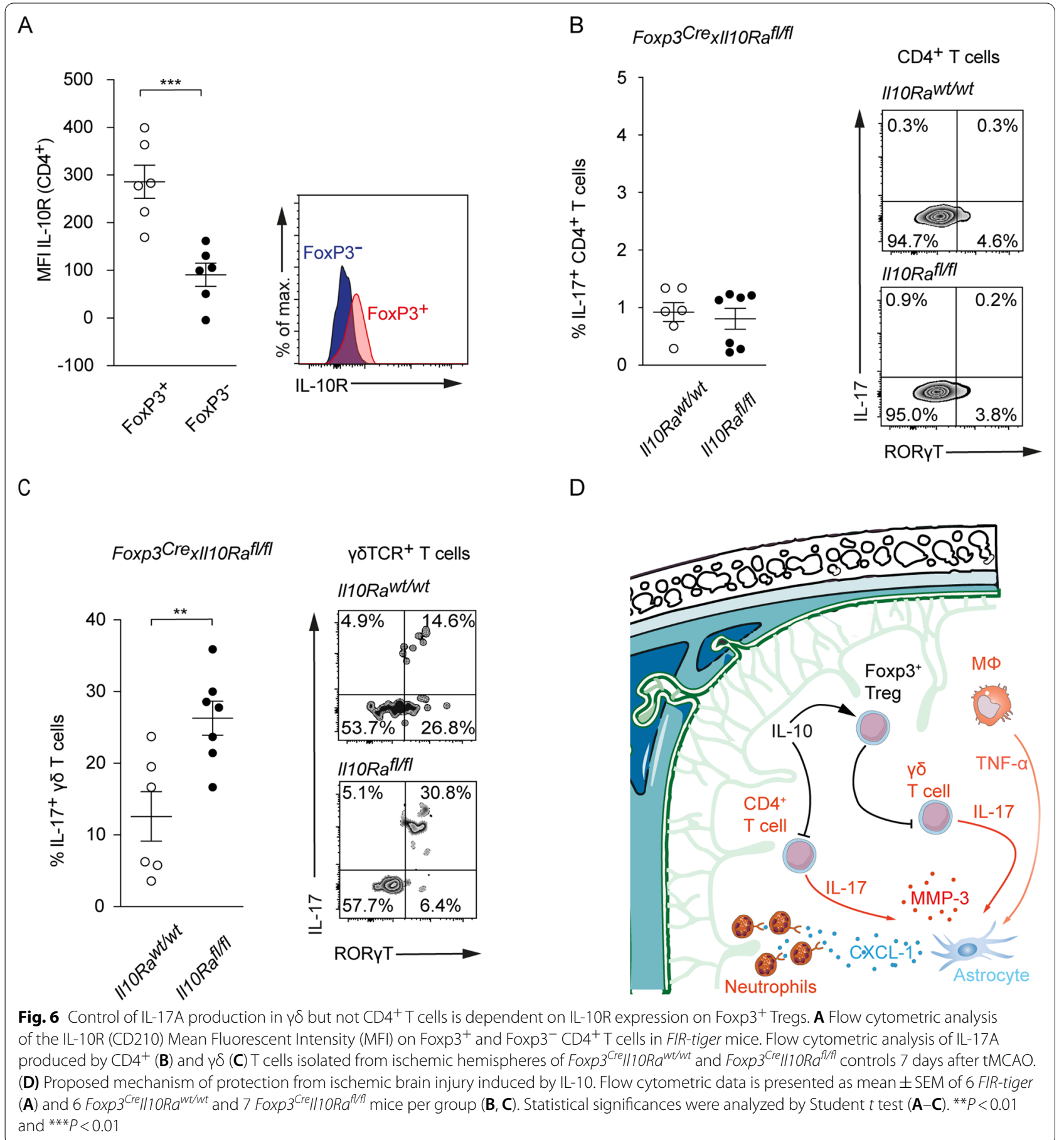

our data indicate that IL-10 not only controls the IL17A driven postischemic inflammatory response in the peripheral immune compartment but also directly in the ischemic brain. We showed that intracerebral injections of recombinant IL-10 reduce the frequency of IL$17 \mathrm{~A}$ producing $\gamma \delta \mathrm{T}$ cells in the ischemic brain following tMCAO.
A strict regulation of IL-17A level in the CNS may also have physiological functions. Recent studies showed that IL-17A ${ }^{+} \gamma \delta \mathrm{T}$ cells populate the meninges from perinatal stages to build a self-renewing pool which controls neuronal signaling, behavior [33], and cognition [34] under homeostatic conditions. The fact that IL-17A can have important homeostatic functions in the brain on the 
one hand and be proinflammatory on the other hand is explained by the physiology of IL-17A signaling. Outcomes of the IL-17A receptor activation depend on the cooperative stimulation by other cytokines, such as IL-1 $\beta$ and TNF- $\alpha$ [35], which are upregulated in the ischemic brain tissue and can lead to synergistic activation of downstream signaling pathways [22]. IL-17A alone is only a modest activator of inflammatory pathways.

During post stroke inflammation, IL-10 seems to directly inhibit the IL-17A production in Th17 cells in ischemic brains, which is a known mechanism from other models of autoimmunity [8]. Accordingly, the targeted deletion of the IL-10R in CD4 ${ }^{+} \mathrm{T}$ cells leads to increased frequencies of Th17 cells in ischemic brains. In contrast to Th17 cells, IL-10 does not directly control IL-17A ${ }^{+}$ $\gamma \delta \mathrm{T}$ cells. Signaling via the IL-10R rather endows Tregs with the capacity to downregulate IL-17A in $\gamma \delta$ T cells. In this study, we did not identify the molecular factor, which enables IL-10R ${ }^{+}$Tregs to inhibit IL-17A ${ }^{+} \gamma \delta$ T cells. Possible candidates include the $\mathrm{B}$ - and T-lymphocyte attenuator and the programmed cell death protein 1 as it has been reported that they negatively regulate IL-17A in a model of psoriatic-like skin inflammation $[26,36]$. A possible role of inhibitory PD-1 signaling to control IL-17A ${ }^{+}$ $\gamma \delta \mathrm{T}$ cells in stroke is supported by our data showing an increased frequency of PD- $1^{+} \mathrm{IL}-17 \mathrm{~A}^{+} \gamma \delta \mathrm{T}$ cells in the ischemic brain when compared to cervical lymph nodes.

Translating findings from animal models to human patients is still challenging. However, we previously showed in autoptic brain tissue that the expression of IL-17A in $\mathrm{T}$ cells goes along with a massive neutrophil infiltration, indicating that the IL-17A-neutrophil axis contributes to human pathophysiology as well [4]. Regarding the potent and pleiotropic immunosuppressive properties of IL-10 on the systemic immune compartment, IL-10 itself might not represent an ideal therapeutic target in stroke. Stroke patients have a significantly increased susceptibility for pneumonia due to aspirations and an immunosuppressive state [37]. Our data show that the worse outcome in $I l 10^{-/-}$mice is largely driven by increased IL-17A levels in the brain, which can be counteracted via neutralization of IL-17A. With this in mind, a targeted antagonization of IL-17A seems promising, irrespective of individual IL-10 levels pre-stroke. Besides, several experimental studies have already shown that the neutralization of IL-17A is protective in stroke $[3,4,24]$. Together with inflammasome activation [38], IL-17A is another conserved signal that orchestrates the amplification of the inflammatory response. In previous studies we observed increased IL-17A levels in ischemic brains as early as $6 \mathrm{~h}$ post stroke [4]. In contrast, the migration of neutrophils into the ischemic brain parenchyma is a comparatively late event during post-stroke inflammation, reaching its maximum at day 3 [4]. Therefore, to effectively target the development of the damaging immune response before it has amplified, anti-inflammatory therapeutic interventions should be given as early as possible. In this respect, it is possible that the therapeutic time window of an IL-17A-neutralization is even below that of thrombolysis, which is currently $6 \mathrm{~h}$. IL-17A antibodies are already approved for the treatment of psoriasis [39] and severe adverse effects on the immune status have, thus far, not been apparent. However, prior to a clinical application of IL-17A antibodies in stroke, longterm data on the effects of IL-17A neutralization in both sexes should be collected to adjust for potential negative effects. This is necessary to exclude that the neutralization has negative long-term consequences on post-stroke regeneration by inhibiting the recently discovered beneficial IL-17A effects on memory and behavior [33, 34].

\section{Conclusion}

In conclusion, our study provides additional insights into the complex interplay between different $\mathrm{T}$ cell subpopulations during post-stroke neuroinflammation. We have shown that IL-10 is pivotal for the control of pathogenic IL-17A ${ }^{+} \alpha \beta$ and $\gamma \delta$ T cells and that an excessive IL-17A production is harmful. Thus, our study improves the understanding of the IL-17A-dependent postischemic inflammatory response and may pave the way towards new immunomodulatory therapies for stroke treatment.

\section{Abbreviations}

IL-17A: Interleukin-17A; tMCAO: Transient middle cerebral artery occlusion; IL-10: Interleukin-10; IL-10R: Interleukin-10-receptor; Tregs: Regulatory T cells; $\mathrm{T}_{\mathrm{R}}$ 1:T regulatory type 1 cells; WT: Wild type; $\mathrm{BSA}$ : Bovine serum albumin; MRI: Magnetic resonance imaging; $1 / 10^{-/-}$: Interleukin-10 knockout; FIR: Foxp3-IRESMRFP; tiger: II10-IRES-GFP-enhanced reporter; CXCL-1: C-X-C Motif Chemokine ligand 1; MMP-3: Matrix Metalloproteinase-3; PD-1: Programmed cell death protein 1.

\section{Supplementary Information}

The online version contains supplementary material available at https://doi. org/10.1186/s12974-021-02316-7.

\footnotetext{
Additional file 1: Figure S1. $/ / 10^{-/-}$mice exhibit worsened neurological scores compared to WT littermate controls, whereas mortality did not differ between groups. (A) Bederson score and survival rate; (B) 14 days after tMCAO in WT control and $/ / 10^{-/-}$mice. Figure S2. Generation of bone-marrow chimeric mice and characterization of post-ischemic IL-10 producers. (A) Generation of bone-marrow chimeras. (B) Representative FACS plots of peripheral blood of bone-marrow chimeras after sacrifice. (C) Flow cytometric analysis of IL-10 produced by B cells, NK cells, CD8 ${ }^{+}$, and $C D 4^{+} T$ cells after sham surgery and 3, 7, and 14 days after stroke in FIR-tiger mice. (D) Expression of Tr1 cell markers CD49b and Lag-3 on $\mathrm{CD}^{+} \mathrm{T}$ cells in spleen and CNS 3 days after tMCAO in FIR-tiger mice. Figure S3. IL-10 deficiency leads to an activation of the IL-17A axis and IL-17A positive $\gamma \delta T$ cellls co-express PD- 1 in the post ischemic brain. (A) Flow cytometric analysis of the number of infiltrating $\mathrm{IL}-17 \mathrm{~A}^{+} \mathrm{CD} 4^{+}$and $\gamma \delta \mathrm{T}$ cells isolated from ischemic hemispheres of WT controls and $/ 110^{-/-}$mice
} 
7 days after tMCAO. (B) Relative gene expression of $\mathrm{CxCl} / 1$ and $\mathrm{Mmp} 3$ in ischemic hemispheres of WT and $/ 110^{-/-}$mice 3 days after tMCAO. (C) Flow cytometric analysis of IL-17 production and PD-1 co-expression by $\mathrm{\gamma} \delta \mathrm{T}$ cells in cervical lymph nodes and the CNS 3 days after stroke.

\section{Acknowledgements}

We thank Ellen Orthey, Anika Ruhl, Mai-Linh Huynh and Oliver Schnapauff for excellent technical assistance. We also thank the FACS Core Facility of the UKE for assistance with the flow cytometry and the departments of Radiology and of Neuroradiology of the UKE for assistance with the MRI measurements.

\section{Disclosure}

None.

\section{Authors' contributions}

$M G, M P, T M$, and $S H$ designed the study. MP, BHC, PL, JV, EJ, LJ, LB, AJ, VR, and ISS conducted various experiments and acquired and analyzed data. TB, BR, IS, $K D, I P, R A F, Y K$, TR and CG provided important reagents and valuable feedback on the manuscript. MG and MP wrote and edited the manuscript. All authors read and approved the final manuscript.

\section{Funding}

Open Access funding enabled and organized by Projekt DEAL. This work was supported by Grants from the Hermann und Lilly Schilling-Foundation for medical research (Prof. Magnus) and the DFG Research Unit FOR 2879 "From immune cells to stroke recovery" (\# 428778375; Dr. Gelderblom and \# 4248778651; Dr. Magnus).

\section{Availability of data and materials}

The data sets used and analyzed during the current study are available from the corresponding author on reasonable request.

\section{Declarations}

\section{Ethics approval and consent to participate}

All animal experiments were approved by local animal care committees (Behörde für Justiz und Verbraucherschutz der Freien und Hansestadt Hamburg; Lebensmittelsicherheit und Veterinärwesen, Hamburg, Germany, permission number: G59/17, N079/19).

\section{Consent for publication}

Not applicable.

\section{Competing interests}

The authors declare that they have no competing interests.

\section{Author details}

'Department of Neurology, University Medical Center Hamburg-Eppendorf, Martinistraße 52, 20246 Hamburg, Germany. ${ }^{2}$ Department of Neurobiology Research, Institute of Molecular Medicine, University of Southern Denmark, Odense, Denmark. ${ }^{3}$ I. Medizinische Klinik, University Medical Center HamburgEppendorf, Hamburg, Germany. ${ }^{4}$ Institute of Immunology, Hannover Medical School, Hannover, Germany. Institute of Systems Immunology, University Medical Center Hamburg-Eppendorf, Hamburg, Germany. ${ }^{6}$ Department of Immunobiology, The Howard Hughes Medical Institute, Yale School of Medicine, New Haven, CT, USA. ${ }^{7}$ Institute of Clinical Chemistry and Laboratory Medicine, University Medical Center Hamburg-Eppendorf, Hamburg, Germany.

Received: 29 June 2021 Accepted: 2 November 2021 Published online: 13 November 2021

\section{References}

1. GN Collaborators. Global, regional, and national burden of neurological disorders, 1990-2016: a systematic analysis for the global burden of disease study 2016. Lancet Neurol. 2019;18:459-80.
2. Iadecola C, Anrather J. The immunology of stroke: from mechanisms to translation. Nat Med. 2011;17:796-808.

3. Shichita T, Sugiyama Y, Ooboshi H, Sugimori H, Nakagawa R, Takada I, et al. Pivotal role of cerebral interleukin-17-producing gammadeltaT cells in the delayed phase of ischemic brain injury. Nat Med. 2009;15:946-50.

4. Gelderblom M, Weymar A, Bernreuther C, Velden J, Arunachalam P, Steinbach $\mathrm{K}$, et al. Neutralization of the IL-17 axis diminishes neutrophil invasion and protects from ischemic stroke. Blood. 2012;120:3793-802.

5. Gelderblom M, Leypoldt F, Steinbach K, Behrens D, Choe CU, Siler DA, et al. Temporal and spatial dynamics of cerebral immune cell accumulation in stroke. Stroke. 2009;40:1849-57.

6. Liesz A, Suri-Payer E, Veltkamp C, Doerr H, Sommer C, Rivest S, et al. Regulatory $T$ cells are key cerebroprotective immunomodulators in acute experimental stroke. Nat Med. 2009;15:192-9.

7. Wendeln AC, Degenhardt K, Kaurani L, Gertig M, Ulas T, Jain G, et al. Innate immune memory in the brain shapes neurological disease hallmarks. Nature. 2018;556:332-8.

8. Huber S, Gagliani N, Esplugues E, O'Connor W Jr, Huber FJ, Chaudhry A, et al. Th17 cells express interleukin-10 receptor and are controlled by Foxp3(-) and Foxp3+ regulatory CD4+ T cells in an interleukin-10-dependent manner. Immunity. 2011;34:554-65.

9. Diefenhardt P, Nosko A, Kluger MA, Richter JV, Wegscheid C, Kobayashi Y, et al. IL-10 receptor signaling empowers regulatory $T$ cells to control Th17 responses and protect from GN. J Am Soc Nephrol. 2018;29:1825-37.

10. Chaudhry A, Samstein RM, Treuting P, Liang Y, Pils MC, Heinrich JM, et al. Interleukin-10 signaling in regulatory $T$ cells is required for suppression of Th17 cell-mediated inflammation. Immunity. 2011;34:566-78.

11. Brockmann L, Gagliani N, Steglich B, Giannou AD, Kempski J, Pelczar P, et al. IL-10 receptor signaling is essential for TR1 cell function in vivo. J Immunol. 2017;198:1130-41.

12. Park SG, Mathur R, Long M, Hosh N, Hao L, Hayden MS, et al. T regulatory cells maintain intestinal homeostasis by suppressing gammadelta $T$ cells. Immunity. 2010;33:791-803.

13. Lee PP, Fitzpatrick DR, Beard C, Jessup HK, Lehar S, Makar KW, et al. A critical role for Dnmt1 and DNA methylation in T cell development, function, and survival. Immunity. 2001;15:763-74.

14. Rubtsov YP, Rasmussen JP, Chi EY, Fontenot J, Castelli L, Ye X, et al. Regulatory $T$ cell-derived interleukin-10 limits inflammation at environmental interfaces. Immunity. 2008;28:546-58.

15. Pils MC, Pisano F, Fasnacht N, Heinrich JM, Groebe L, Schippers A, et al. Monocytes/macrophages and/or neutrophils are the target of IL-10 in the LPS endotoxemia model. Eur J Immunol. 2010;40:443-8.

16. Wan YY, Flavell RA. Identifying Foxp3-expressing suppressor T cells with a bicistronic reporter. Proc Natl Acad Sci USA. 2005;102:5126-31.

17. Kamanaka M, Kim ST, Wan YY, Sutterwala FS, Lara-Tejero M, Galan JE, et al. Expression of interleukin-10 in intestinal lymphocytes detected by an interleukin-10 reporter knockin tiger mouse. Immunity. 2006;25:941-52.

18. Zhang B, Wu J, Jiao Y, Bock C, Dai M, Chen B, et al. Differential requirements of TCR signaling in homeostatic maintenance and function of dendritic epidermal T cells. J Immunol. 2015;195:4282-91.

19. Mracsko E, Javidi E, Na SY, Kahn A, Liesz A, Veltkamp R. Leukocyte invasion of the brain after experimental intracerebral hemorrhage in mice. Stroke. 2014;45:2107-14.

20. Orsini F, Villa P, Parrella S, Zangari R, Zanier ER, Gesuete R, et al. Targeting mannose-binding lectin confers long-lasting protection with a surprisingly wide therapeutic window in cerebral ischemia. Circulation. 2012;126:1484-94.

21. Gelderblom M, Melzer N, Schattling B, Gob E, Hicking G, Arunachalam P, et al. Transient receptor potential melastatin subfamily member 2 cation channel regulates detrimental immune cell invasion in ischemic stroke. Stroke. 2014;45:3395-402.

22. Clausen BH, Lambertsen KL, Babcock AA, Holm TH, Dagnaes-Hansen F, Finsen $B$. Interleukin-1 beta and tumor necrosis factor-alpha are expressed by different subsets of microglia and macrophages after ischemic stroke in mice. J Neuroinflammation. 2008;5:46.

23. Gagliani N, Magnani CF, Huber S, Gianolini ME, Pala M, Licona-Limon P, et al. Coexpression of CD49b and LAG-3 identifies human and mouse T regulatory type 1 cells. Nat Med. 2013;19:739-46.

24. Benakis C, Brea D, Caballero S, Faraco G, Moore J, Murphy M, et al. Commensal microbiota affects ischemic stroke outcome by regulating intestinal gammadelta T cells. Nat Med. 2016;22:516-23. 
25. Iwakura Y, Ishigame H, Saijo S, Nakae S. Functional specialization of interleukin-17 family members. Immunity. 2011;34:149-62.

26. Imai Y, Ayithan N, Wu X, Yuan Y, Wang L, Hwang ST. Cutting edge: PD-1 regulates imiquimod-induced psoriasiform dermatitis through inhibition of IL-17A expression by Innate gammadelta-low T cells. J Immunol. 2015;195:421-5.

27. Jankovic D, Kullberg MC, Feng CG, Goldszmid RS, Collazo CM, Wilson M, et al. Conventional T-bet(+)Foxp3(-) Th1 cells are the major source of host-protective regulatory IL-10 during intracellular protozoan infection. J Exp Med. 2007;204:273-83.

28. Laouini D, Alenius H, Bryce $P$, Oettgen $H$, Tsitsikov E, Geha RS. IL-10 is critical for Th2 responses in a murine model of allergic dermatitis. J Clin Invest. 2003;112:1058-66.

29. Gagliani N, Amezcua Vesely MC, Iseppon A, Brockmann L, Xu H, Palm NW, et al. Th17 cells transdifferentiate into regulatory $T$ cells during resolution of inflammation. Nature. 2015;523:221-5.

30. Bodhankar S, Chen Y, Vandenbark AA, Murphy SJ, Offner H. IL-10-producing B-cells limit CNS inflammation and infarct volume in experimental stroke. Metab Brain Dis. 2013;28:375-86.

31. He ML, Lv ZY, Shi X, Yang T, Zhang Y, Li TY, et al. Interleukin-10 release from astrocytes suppresses neuronal apoptosis via the TLR2/NFkappaB pathway in a neonatal rat model of hypoxic-ischemic brain damage. J Neurochem. 2017;142:920-33.

32. Ren $X$, Akiyoshi $K$, Dziennis $S$, Vandenbark AA, Herson PS, Hurn PD, et al. Regulatory B cells limit CNS inflammation and neurologic deficits in murine experimental stroke. J Neurosci. 2011;31:8556-63.

33. Alves de Lima K, Rustenhoven J, Da Mesquita S, Wall M, Salvador AF, Smirnov I, et al. Meningeal $\gamma \delta$ T cells regulate anxiety-like behavior via IL-17a signaling in neurons. Nat Immunol. 2020;21:1421-9.
34. Ribeiro M, Brigas HC, Temido-Ferreira M, Pousinha PA, Regen T, Santa C, et al. Meningeal gammadelta T cell-derived IL-17 controls synaptic plasticity and short-term memory. Sci Immunol. 2019;4:eaay5199.

35. Ruddy MJ, Wong GC, Liu XK, Yamamoto H, Kasayama S, Kirkwood KL, et al. Functional cooperation between interleukin-17 and tumor necrosis factor-alpha is mediated by CCAAT/enhancer-binding protein family members. J Biol Chem. 2004;279:2559-67.

36. Bekiaris V, Sedy JR, Macauley MG, Rhode-Kurnow A, Ware CF. The inhibitory receptor BTLA controls gammadelta T cell homeostasis and inflammatory responses. Immunity. 2013;39:1082-94.

37. Meisel C, Schwab JM, Prass K, Meisel A, Dirnagl U. Central nervous system injury-induced immune deficiency syndrome. Nat Rev Neurosci. 2005;6:775-86.

38. Wang H, Chen H, Jin J, Liu Q, Zhong D, Li G. Inhibition of the NLRP3 inflammasome reduces brain edema and regulates the distribution of aquaporin-4 after cerebral ischaemia-reperfusion. Life Sci. 2020;251:117638.

39. Chiricozzi A, Krueger JG. IL-17 targeted therapies for psoriasis. Expert Opin Investig Drugs. 2013;22:993-1005.

\section{Publisher's Note}

Springer Nature remains neutral with regard to jurisdictional claims in published maps and institutional affiliations.
Ready to submit your research? Choose BMC and benefit from:

- fast, convenient online submission

- thorough peer review by experienced researchers in your field

- rapid publication on acceptance

- support for research data, including large and complex data types

- gold Open Access which fosters wider collaboration and increased citations

- maximum visibility for your research: over $100 \mathrm{M}$ website views per year

At BMC, research is always in progress.

Learn more biomedcentral.com/submissions 